\title{
Self-Assembled Mannan Nanogel: Cytocompatibility and Cell Localization
}

\author{
Sílvia A. Ferreira ${ }^{1}$, Vera Carvalho ${ }^{1}$, Carla Costa ${ }^{2}$, João Paulo Teixeira ${ }^{2}$, \\ Manuel Vilanova ${ }^{3,4}$, and Francisco M. Gama ${ }^{1, *}$ \\ ${ }^{1}$ Institute for Biotechnology and Bioengineering, Centre for Biological Engineering, \\ University of Minho, Campus Gualtar, 4710-057 Braga, Portugal \\ ${ }^{2}$ National Institute of Health, Environmental Health Department, \\ Rua Alexandre Herculano 321, 4000-055 Porto, Portugal \\ ${ }^{3}$ Abel Salazar Biomedical Sciences Institute, University of Porto, \\ Largo do Professor Abel Salazar 2, 4099-003, Porto, Portugal \\ ${ }^{4}$ Institute of Molecular and Cell Biology, Rua do Campo Alegre 823 \\ 4150-180 Porto, Portugal
}

\begin{abstract}
Amphiphilic mannan, produced by the Michael addition of hydrophobic 1-hexadecanethiol to vinyl methacrylated mannan, self-assembles in aqueous medium through hydrophobic interactions among alkyl chains. Resultant nanogel is stable, spherical, polydisperse, with $50-140 \mathrm{~nm}$ mean hydrodynamic diameter depending on the polymer degree of substitution, and nearly neutral negative surface charge. No cytotoxicity of mannan nanogel is detected up to about $0.4 \mathrm{mg} / \mathrm{mL}$ in mouse embryo fibroblast cell line 3 T3 and mouse bone marrow-derived macrophages (BMDM) using cell proliferation, lactate dehydrogenase and Live/Dead assays. Comet assay, under the tested conditions, reveals no DNA damage in fibroblasts but possible in BMDM. BMDM internalize the mannan nanogel, which is observed in vesicles in the cytoplasm by confocal laser scanning microscopy. Confocal colocalization image analysis denotes that the entrance and exit of nanogel and FM 4-64 might occur by the same processes - endocytosis and exocytosis - in BMDM. Physicochemical characteristics, in vitro cytocompatibility and uptake of self-assembled mannan nanogel by mouse BMDM are great signals of the potential applicability of this nanosystem for macrophages targeted delivery of vaccines or drugs, acting as potential nanomedicines, always with the key goal of preventing and/or treating diseases.
\end{abstract}

Keywords: Colloidal Dispersion, Confocal Colocalization, Cytocompatibility, Image Analysis, Mannan Nanogel, Self-Assembly, Uptake.

\section{INTRODUCTION}

The performance of nanogels as carriers intended to deliver biologically active agents to specific targets are mainly regulated by their physicochemical properties. These properties include hydrophilicity, surface charge, size, shape, composition, concentration, and presence of various ligands, which ultimately govern their interaction with proteins, perturbation of the cell membranes, cell activation, cellular uptake, intracellular localization and removal of nanomaterials by cells, cell necrosis or apoptosis, gene regulation, effects on cell signaling, influence

\footnotetext{
*Author to whom correspondence should be addressed.
}

on the cellular electron transfer cascades, production of cytokines, chemokines and reactive oxygen species. ${ }^{1-3}$

Amphiphilic mannan, self-assembled in nanometersized supramolecular hydrogels - i.e., hydrogel nanoparticles or nanogels - were developed in previous work, ${ }^{4}$ aiming the drug targeted delivery to mannose receptors expressed in the surface of antigen-presenting cells (APC).$^{5-8}$ Similarly, mannan-coated gelatin nanoparticles targeted didanosine, an anti-HIV drug, to macrophages both in vitro and in vivo. ${ }^{9}$ Moreover, mannosylated chitosan nanoparticle-based murine interleukin-12 (IL-12) gene therapy suppressed cancer growth and angiogenesis, and significantly induced cell cycle arrest and apoptosis in BALB/c mice bearing CT-26 carcinoma cells. ${ }^{10}$ Mannose 
receptor participates in mannose receptor-mediated endocytosis contributing to the host defense, providing a linkage between innate and adaptive immunity. ${ }^{8,11-13}$ Plasmid DNA encoding $\beta$-galactosidase, used as a model antigen, coated on the surface of mannan coated-nanoparticles resulted in a significant enhancement in both antigenspecific immunoglobulin $\mathrm{G}$ ( $\mathrm{IgG})$ titers and splenocyte proliferation over 'naked' plasmid DNA alone upon topical application in mice. ${ }^{14}$ Cholesterol-bearing mannan (CHM) complexed with human epidermal growth factor receptor 2 (HER2) oncoprotein, encoded by the HER2/neu/cerbB2 oncogene, containing the $147 \mathrm{~N}$-terminal amino acids were able to induce $\mathrm{CD} 8^{+} \mathrm{CTL}$ against $\mathrm{HER} 2^{+}$ tumors and to strongly enhance the production of $\mathrm{IgG}$ antibodies against HER2 in mice immunized subcutaneously. Mice immunized with CHM-HER2 before or early after tumor challenge successfully rejected HER2-transfected tumors. ${ }^{15,16}$

The particles of the mannan nanogel are stable, spherical, polydisperse, with mean hydrodynamic diameter or $z$-average ranging between 50 and $140 \mathrm{~nm}$ depending on the polymer degree of substitution, and with nearly neutral negative surface charge or zeta potential, as previously studied. ${ }^{4}$ Mannan nanogel spontaneously incorporated bovine serum albumin and curcumin indicating its potential as delivery systems for therapeutic molecules. ${ }^{4}$ In the present work, the essential focus was to assess nanomaterial cytocompatibility and to analyze the internalization by macrophages. The mannan nanogel cytocompatibility was tested in mouse embryo fibroblast cell line 3T3 and mouse bone marrow-derived macrophages (BMDM), using the CellTiter $96^{\circledR} \mathrm{AQ}_{\text {ueous }}$ one-solution cell proliferation assay, lactate dehydrogenase (LDH) cytotoxicity detection $\mathrm{kit}^{\text {PLUS }}$ and LIVE/DEAD ${ }^{\circledR}$ viability/cytotoxicity kit for mammalian cells. Genotoxicity was evaluated with comet assay. Uptake of mannan nanogel labeled with a fluorochrome probe by the BMDM was studied by confocal laser scanning microscopy (CLSM).

\section{MATERIAL AND METHODS}

\subsection{Materials}

Mannan-VMA-SC 16 (VMA: vinyl methacrylate, $\mathrm{SC}_{16}$ : hydrophobic alkyl chain) was synthesized as described previously. ${ }^{4}$ According to the polymer degree of substitution (DS), defined as the percentage of grafted acrylate groups $\left(\mathrm{DS}_{\mathrm{VMA}}\right)$ or alkyl chains $\left(\mathrm{DS}_{\mathrm{C} 16}\right)$ relative to the mannose residues, samples of mannan- $\mathrm{C}_{16}$ nanogel were named as $\mathrm{MVC}_{16}-\mathrm{DS}_{\mathrm{VMA}}-\mathrm{DS}_{\mathrm{C} 16}$. Three batches were studied: $\mathrm{MVC}_{16}-25-11, \mathrm{MVC}_{16}-25-22$ and $\mathrm{MVC}_{16}-31-20$. Organic and inorganic reagents of laboratory grade were purchased from Sigma and used without any further purification. All cell culture products were of cell culture grade and purchased from Sigma, saving reported exceptions.

\subsection{Preparation of Self-Assembled Mannan Nanogel}

Each sterile stock colloidal dispersion of mannan- $\mathrm{C}_{16}$ was prepared stirring the lyophilized mannan- $\mathrm{C}_{16}$ in phosphate buffer saline, $\mathrm{pH} 7.4$ (PBS), for $3-5$ days at $50{ }^{\circ} \mathrm{C}$, followed by sterilized filtration (Orange; pore size $0.22 \mu \mathrm{m}$ ). The nanogel formation was confirmed by dynamic light scattering (DLS). The size distribution and zeta potential measurements were performed in a Malvern Zetasizer NANO ZS (Malvern Instruments Limited, UK) as previously described. ${ }^{4}$ Serial dilutions were prepared in sterile apyrogenic PBS and final sample concentration was adjusted diluting five times with culture medium.

\subsection{Cell Culture}

\subsubsection{Fibroblast Cell Line $3 \mathrm{T3}$}

Mouse embryo fibroblast cell line 3T3 (ATCC CCL164) was grown in Dulbecco's modified Eagle's media (DMEM; $4.5 \mathrm{~g} / \mathrm{L}$ glucose) supplemented with $10 \%$ newborn calf serum (Invitrogen, UK), $100 \mathrm{IU} / \mathrm{mL}$ penicillin and $0.1 \mathrm{mg} / \mathrm{mL}$ streptomycin at $37{ }^{\circ} \mathrm{C}$ in a $95 \%$ humidified air containing $5 \% \mathrm{CO}_{2}$. At confluence, fibroblasts were harvested with $0.05 \%(\mathrm{w} / \mathrm{v})$ trypsin-EDTA, adjusted to the required concentration of viable cells - determined using the Trypan blue exclusion assay, indicative of plasma membrane integrity - and were subcultivated in the same medium. Fibroblasts were plated at $4 \times 10^{3}$ cells $/ 200 \mu \mathrm{L} /$ well for cell proliferation assay, $1 \times 10^{4}$ cells/200 $\mu \mathrm{L} /$ well for $\mathrm{LDH}$ assay or $4 \times 10^{5}$ cells $/ 200 \mu \mathrm{L} /$ well for comet assay in 96-well plates (Sarstedt, Canada) and $1 \times 10^{5}$ cells $/ 2 \mathrm{~mL} /$ well for live/dead assay in 6-well plates (Sarstedt, Canada). Then fibroblasts were incubated $5 \mathrm{~h}$ at $37{ }^{\circ} \mathrm{C}$ in a $95 \%$ humidified air containing $5 \% \mathrm{CO}_{2}$.

\subsubsection{Mouse BMDM}

Female BALB/c mice (6-8 weeks old) were purchased from Charles River (Barcelona, Spain). Animals were kept at the animal facilities of the Institute Abel Salazar during the experiments. Hiding and nesting materials were provided as enrichment. Procedures involving mice were performed according to the European Convention for the Protection of Vertebrate Animals used for Experimental and Other Scientific Purposes (ETS 123) and 86/609/EEC Directive and Portuguese rules (DL 129/92). In order to obtain mouse BMDM femurs and tibias were collected under aseptic conditions and flushed with Hanks' balanced salt solution. The resulting cell suspension was centrifuged at $500 \times g$ and resuspended in RPMI 1640 medium supplemented with $10 \mathrm{mM}$ HEPES, $10 \%$ heatinactivated fetal bovine serum (FBS), $60 \mathrm{IU} / \mathrm{mL}$ penicillin, $60 \mu \mathrm{g} / \mathrm{mL}$ streptomycin, $0.5 \mathrm{mM} \beta$-mercaptoethanol (complete RPMI [cRPMI]), and 10\% L929 cell conditioned medium (LCCM). To remove fibroblasts or 
differentiated macrophages, cells were cultured, on cell culture dishes (Sarstedt, Canada), overnight at $37{ }^{\circ} \mathrm{C}$ in a $95 \%$ humidified air containing $5 \% \quad \mathrm{CO}_{2}$. Then, nonadherent cells were collected with warm cRPMI, centrifuged at $500 \times g$, ressuspended in cRPMI and distributed $2 \times 10^{4}$ cells $/ 200 \mu \mathrm{L} /$ well in 96 -well plates for cell proliferation and $\mathrm{LDH}$ assays, $1 \times 10^{5}$ cells $/ 1 \mathrm{~mL} /$ well in 24-well plates (Sarstedt, Canada) for comet assay, $2 \times 10^{5}$ cells $/ 2 \mathrm{~mL} /$ well in 6 -well plates for live/dead assay, and $5 \times 10^{5}$ cells $/ 1 \mathrm{~mL} /$ well in 24 -well plates or $1 \times 10^{6}$ cells $/ 2 \mathrm{~mL} /$ fluorodish (WPI, UK) for confocal studies. Cells were then incubated at $37{ }^{\circ} \mathrm{C}$ in a $95 \%$ humidified air containing $5 \% \mathrm{CO}_{2}$. Four days after seeding, $10 \%$ of LCCM was added, and the medium was renewed on the seventh day. After 10 days in culture, cells were completely differentiated into macrophages. This method allows for the differentiation of a homogenous primary culture of macrophages that retain the morphological, physiological and surface markers characteristics of these phagocytic cells. ${ }^{17-19}$

\subsection{Effect of Mannan Nanogel on Cell Viability and Cell Proliferation}

\subsubsection{Cell Proliferation Assay}

The cell viability was determined by CellTiter $96^{\circledR} \mathrm{AQ}_{\text {ueous }}$ one-solution non-radioactive cell proliferation assay (Promega, USA) composed by 3-(4,5-dimethylthiazol2-yl)-5-(3-carboxymethoxyphenyl)-2-(4-sulfophenyl)-2Htetrazolium (MTS) and an electron coupling reagent (phenazine methosulfate; PMS). Nanogel at different concentrations was incubated with mouse fibroblast 3T3 cells and mouse BMDM, for 24 or $48 \mathrm{~h}$ at $37{ }^{\circ} \mathrm{C}$, in a $95 \%$ humidified air containing $5 \% \mathrm{CO}_{2}$. Then, each well was washed with $100 \mu \mathrm{L}$ of fresh cell culture medium and MTS $(20 \mu \mathrm{L})$ was added. After $1 \mathrm{~h}$ of incubation in same conditions, MTS is bioreduced by dehydrogenase enzymes found in metabolically active cells into a formazan product that is soluble in culture medium. The UV absorbance of the formazan was measured at $490 \mathrm{~nm}$ in an automated ELISA plate reader, which is directly proportional to the number of living cells in culture. The results were compared to a control prepared with the same cell culture medium without the addition of nanogel. The results are expressed as cell proliferation index (CPI) after normalizing the viability of untreated cells to $100 \%$.

\subsubsection{LDH Assay}

The cytotoxicity/cytolysis of mannan nanogel to mouse fibroblast $3 \mathrm{~T} 3$ cells and mouse BMDM, after $3 \mathrm{~h}$ and $20 \mathrm{~h}$ of incubation at $37{ }^{\circ} \mathrm{C}$, in a $95 \%$ humidified air containing $5 \% \mathrm{CO}_{2}$ was evaluated using LDH Cytotoxicity Detection $\mathrm{Kit}^{\mathrm{PLUS}}$ (Roche, Germany), following the manufacturer instructions. Preliminary assays were carried out to determine the optimal cell concentration and to confirm that nanogel did not interfere with the assay, using culture medium with $1 \%$ of serum and without sodium pyruvate. The results are expressed in absorbance values, after subtracting the background control to the average of the triplicate samples and controls absorbance values, measured at $490 \mathrm{~nm}$ in an automated ELISA, using as reference the absorbance obtained at $620 \mathrm{~nm}$.

\subsubsection{Live/Dead Assay}

The Live/Dead ${ }^{\circledR}$ viability/cytotoxicity kit for mammalian cells (Invitrogen, UK) was used to determine mouse fibroblast 3T3 cells and mouse BMDM viability in presence of nanogel incubated with cells at different concentrations, for $24 \mathrm{~h}$ at $37{ }^{\circ} \mathrm{C}$, in a $95 \%$ humidified air containing $5 \% \mathrm{CO}_{2}$. At the end, $100 \mu \mathrm{L}$ of a solution with $2 \mu \mathrm{M}$ calcein AM and $4 \mu \mathrm{M}$ ethidium homodimer-1 in sterile PBS was added to each well. After incubation for 30-45 min in the same conditions as above, cells were visualized in a fluorescence microscope Olympus BX-61 Fluorescence Microscope (Olympus, Germany) coupled with a DP70 digital camera (Melville, NY) using objective $10 \times$. Images were analyzed with Cell-P software (Olympus, Germany).

\subsubsection{Comet Assay}

Nanogel at different concentrations was incubated with mouse fibroblast 3T3 cells and mouse BMDM, for 24 or $48 \mathrm{~h}$ at $37{ }^{\circ} \mathrm{C}$, in a $95 \%$ humidified air containing $5 \% \mathrm{CO}_{2}$. After the period of incubation, fibroblasts were harvested with $0.05 \%(\mathrm{w} / \mathrm{v})$ trypsin-EDTA and macrophages were mechanically harvested, and washed three times with ice cold PBS, pH 7.4. Cell viability, determined by trypan blue exclusion, was higher than $80 \%$ in all cases. The alkaline version of the comet assay was performed as described by Singh et al. ${ }^{20}$ with minor modifications. Briefly, cells collected by centrifugation $(7500 \times g$ for $3 \mathrm{~min})$ and suspended in $120 \mu \mathrm{L}$ of $0.6 \%$ low melting point agarose in PBS were dropped onto a frosted slide precoated with a layer of $1 \%$ normal melting point agarose. Slides were placed on ice for $4 \mathrm{~min}$ and allowed to solidify. Coverslips were then removed and slides were immersed in freshly prepared lysing solution $\left(2.5 \mathrm{M} \mathrm{NaCl}, 100 \mathrm{mM} \mathrm{Na}{ }_{2}\right.$ EDTA, $10 \mathrm{mM}$ TrisBase, $10 \mathrm{M} \mathrm{NaOH}, \mathrm{pH} 10$ ) for $1 \mathrm{~h}$ at $4{ }^{\circ} \mathrm{C}$, in the dark. After lysis, slides were washed with ice water and placed on a horizontal electrophoresis tank in an ice bath. The tank was filled with freshly made alkaline electrophoresis solution $\left(1 \mathrm{mM} \mathrm{Na}{ }_{2}\right.$ EDTA, $300 \mathrm{mM} \mathrm{NaOH}$, $\mathrm{pH}$ 13) to cover the slides, that were left for $20 \mathrm{~min}$ in the dark to allow DNA unwinding and alkalilabile site expression. Electrophoresis was carried out for $20 \mathrm{~min}$ at $30 \mathrm{~V}$ and $300 \mathrm{~mA}(1 \mathrm{~V} / \mathrm{cm})$. The slides were then washed for 10 min with $1 \mathrm{~mL}$ of neutralizing solution (0.4 M TrisBase, 
$\mathrm{pH}$ 7.5). After neutralization, gels were dried overnight in the dark. Then in the dark the gels were rehydrated with ice cold water and stained with ethidium bromide solution $(20 \mu \mathrm{g} / \mathrm{mL})$ for $20 \mathrm{~min}$. After staining the slides were washed twice with ice cold bidistilled water for $20 \mathrm{~min}$ and dried. Before observation with the fluorescence microscope the dried slide was rehydrated and covered with a coverslip. Two slides were prepared for each treatment with nanogel and a 'blind' scorer examined 100 randomly selected cells per replicate using a magnification of $400 \times$. Image capture by an on-line CCD camera and analysis were performed with Comet Assay IV software (Perceptive Instruments).

\subsection{Uptake of Mannan Nanogel by the BMDM}

\subsubsection{Mannan Nanogel Labeled with SAMSA Fluorescein}

Synthesis of mannan- $\mathrm{C}_{16}$ labeled with 5-((2-(and-3)S-(acetylmercapto)succinoyl)amino)fluorescein (SAMSA fluorescein; Molecular Probes, Invitrogen) was based on the reaction between the thiol group of SAMSA fluorescein with the grafted methacrylate not substituted with $\mathrm{C}_{16}$ of $\mathrm{MVC}_{16}-31-20$, as previously described. ${ }^{4}$ Labeling did not affect the properties of the nanogel, as estimated by DLS.

\subsection{Confocal Studies}

In order to evaluate the phagocytic activity, mouse BMDM $\left(5 \times 10^{5}\right.$ cells/well) were seeded on coverslips (Sarstedt, Canada) and stimulated with and without lipopolysaccharide (LPS from E. coli; $100 \mathrm{ng} / \mathrm{mL}$ ) and interferon- $\gamma$ (IFN- $\gamma ; 1 \mathrm{ng} / \mathrm{mL} ; \mathrm{R} \& \mathrm{D}$ systems). Then, the macrophages were incubated with or without mannan nanogel labeled with SAMSA fluorescein $(0.1 \mathrm{mg} / \mathrm{mL}$; emission wavelength $\left.\left(\lambda_{\text {em }}\right) 519 \mathrm{~nm}\right)$ for $6 \mathrm{~h}$. The coverslips were washed twice with PBS and cells were fixed with methanol absolute $\left(-20^{\circ} \mathrm{C}\right)$ for $10 \mathrm{~min}$. Following PBS washing (twice), nuclei were stained with 4'-6-diamidino-2-phenylindole (DAPI; $\left(\lambda_{\text {em }}\right) 461 \mathrm{~nm}$ ) using vectashield mounting medium (Vector Laboratories) as an anti-fading. $Z$-series of cells with $284.90 \mathrm{~nm} Z$ spacing between image planes, with $5 \times$ optical zoom and $512 \times 512$ pixel size were obtained using confocal laser scanning microscope Leica SP2 AOBS SE (Leica Microsystems, Germany), an inverted microscope Leica DMIRE2 equipped with objective HC PL APO Lbl. Blue $63 \times$ with a numerical aperture of 1.40 Oil LEICA, and confocal software LCS 2.61 (Leica Microsystems, Germany).

The internalization of nanogel by BMDM plated in fluorodish (WPI, UK) was followed by the CLSM. Live cells nuclei' were labeled with DAPI $(0.05 \mathrm{mg} / \mathrm{mL})$ for $3 \mathrm{~min}$ at room temperature in cRPMI. After washing, cells were incubated for 20 min with $20 \mu \mathrm{M}$ FM 4-64 ${ }^{\circledR}$
(Molecular Probes, Invitrogen, $\lambda_{\mathrm{em}} 618 \mathrm{~nm}$ ) in cRPMI. Membranes are intensely red-fluorescent labeled when FM 4-64 inserts into the outer leaflet of the surface membrane. FM 4-64 is frequently used in endocytosis and exocytosis studies in eukaryotic cells because it is water-soluble, nontoxic to cells and virtually nonfluorescent in aqueous media. Propidium iodide (PI, $1 \mu \mathrm{g} / \mathrm{mL}$ ) was added to the medium to evaluate the viability of the cells. The plate was then placed on the stage of the confocal laser scanning microscope (OLYMPUS FluoView ${ }^{\mathrm{TM}}$ - FV1000) at $37{ }^{\circ} \mathrm{C}$ and $5 \% \quad \mathrm{CO}_{2}$. A representative area of the fluorodish was selected at random and control picture was obtained. Labeled nanogel was then added into the medium $(0.1 \mathrm{mg} / \mathrm{mL})$. Five $z$-series with $0.98 \mu \mathrm{m} Z$ spacing between image planes and time-series with $15 \mathrm{~min}$ interval were obtained using 3 lasers $(405 \mathrm{~nm}, 488 \mathrm{~nm}$ and $559 \mathrm{~nm}$ ) in the three narrow bandwidth emission filter, sequential acquisition and kalman filter mode, $40 \times$ objective with a numerical aperture of $0.9,2 \times$ optical zoom, and $640 \times 640$ pixel size with four detectors. To follow the exocytosis of the nanogel, the incubating medium was carefully removed from the fluorodish, washed three times with PBS and then filled with fresh medium with PI. Another series of time scans were obtained as described before. All confocal images were obtained under identical scan settings. Control specimens were prepared with each fluorochrome separately and in the absence of staining for excitation cross-talk and emission bleed-through analysis, and autofluorescence characterization, respectively. In time lapses, threshold-based analysis (annotation) measurements were performed with software Olympus FluoView1000 (FV viewer v.2.0), after removing unspecific events generated by noise and background, using a twodimensional scatterplot of intensity ranges of red channel versus green channel, where thresholds were defined using the controls results. Colocalization coefficient in total pixels area $\left(C_{\mathrm{T}}\right.$, correspondent to the ratio between colocalized pixels and total number of pixels) was calculated in two-color - red and green corresponding to FM 4-64 and labeled nanogel - two-dimensional microscopic images. Reported values of $C_{\mathrm{T}}$ for each time correspond to mean obtained using "regions of interest" (ROIs) corresponding to cytoplasm of 45 cells.

\subsection{Statistical Analysis}

Statistical significance of the cytotoxicity and genotoxicity results was determined by one-way analysis of variance (ANOVA) with Dunnett's post-test using GraphPad Prism version 4.00 for Windows (GraphPad Software, San Diego California USA). Statistical significant differences within results obtained with each concentration of nanogels in comparison with the control at same incubation period were labeled with a single asterisk $(p<0.05)$ and with two asterisks $(p<0.01)$. 
Table I. Size and zeta potential measurements obtained in DLS for mannan nanogel at $1 \mathrm{mg} / \mathrm{mL}$ in PBS.

\begin{tabular}{lccl}
\hline & $\mathrm{MVC}_{16}-25-11$ & $\mathrm{MVC}_{16}-25-22$ & $\mathrm{MVC}_{16}-31-20$ \\
\hline$Z$-average (nm) & $50.7 \pm 0.9$ & $56.4 \pm 1.5$ & $109.0 \pm 2.9$ \\
Polydispersity Index (PdI) $0.589 \pm 0.010$ & $0.431 \pm 0.010$ & $0.431 \pm 0.056$ \\
Zeta potential (mV) & $-8.49 \pm 1.71$ & $-10.49 \pm 3.76$ & $-7.29 \pm 0.37$ \\
\hline
\end{tabular}

(mean \pm S.D., $n=10$ ).

\section{RESULTS AND DISCUSSION}

\subsection{Cytocompatibility of Mannan Nanogel}

Self-assembled amphiphilic mannan nanogel, with different $\mathrm{DS}_{\mathrm{C} 16}-\mathrm{MVC}_{16}-25-11$ and $\mathrm{MVC}_{16}-25-22$ - and different $\mathrm{DS}_{\mathrm{VMA}}-\mathrm{MVC}_{16}-25-22$ and $\mathrm{MVC}_{16}-31-20$, corresponding to different nanogel size (Table I), were selected to study the cytocompatibility of the nanogel using cell proliferation, LDH and Live/Dead assays.

Cell proliferation assay using MTS is a colorimetric, easy, fast and safe assay that measures the mitochondrial metabolic activity. ${ }^{21,22}$ MTS assay (Fig. 1) showed that,
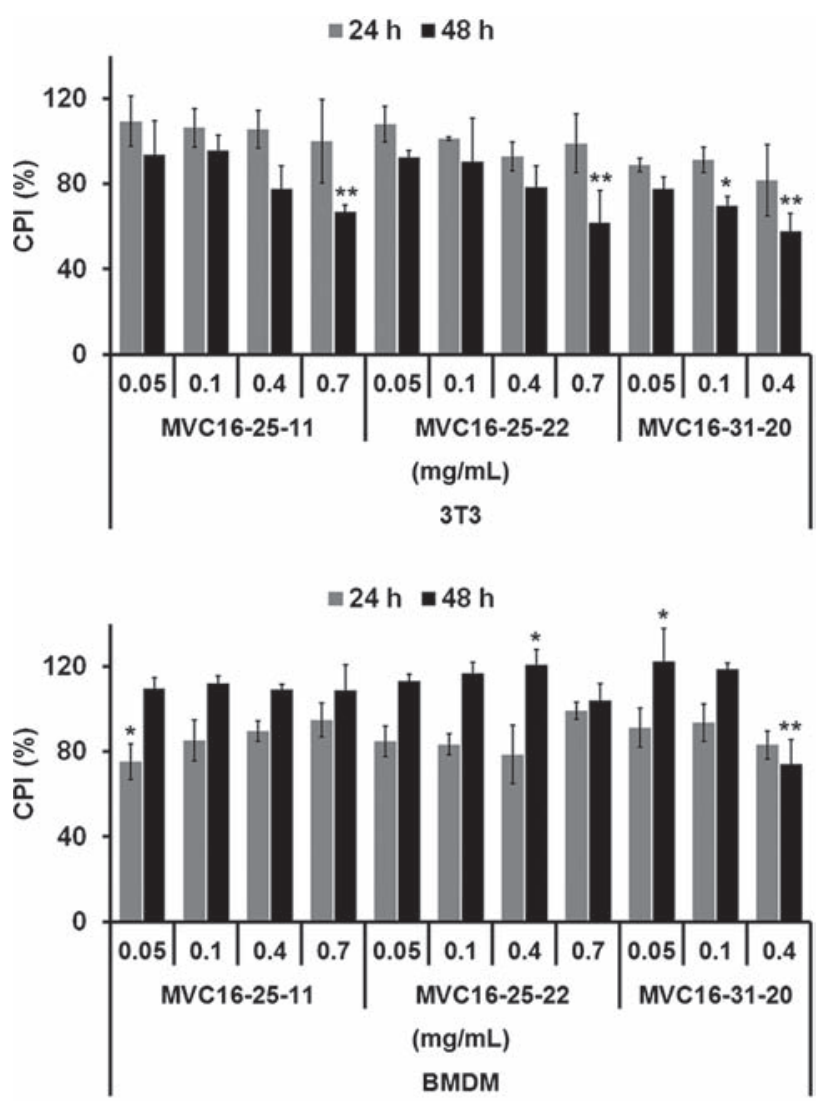

Fig. 1. Effect of mannan nanogel, at the indicated concentrations, in mouse embryo fibroblast 3T3 cells and BMDM, assessed with the MTS assay. Results correspond to the mean \pm standard deviation (S.D.) of the cell proliferation index $\left(\mathrm{CPI},{ }^{*} p<0.05\right.$ and $\left.{ }^{* *} p<0.01\right)$, obtained for the different groups at $24 \mathrm{~h}$ and $48 \mathrm{~h}$ of incubation with mannan nanogel at the indicated concentrations. The results shown are from one experiment, representative of three independent experiments performed in triplicate. after $24 \mathrm{~h}$ of incubation, the viability of mouse embryo fibroblast 3T3 was not significantly affected by any of the concentrations of the three batches of mannan nanogel used. After $48 \mathrm{~h}$ of incubation, the toxicity of the nanogel was dose dependent and significant for the higher concentrations of each batch. Fibroblasts proliferated normally. The viability of mouse BMDM after $24 \mathrm{~h}$ of incubation was overall not affected by the nanogel, being significantly reduced only for $\mathrm{MVC}_{16}-25-11$ at $0.05 \mathrm{mg} / \mathrm{mL}$, where the CPI was close to $75 \%$. After $48 \mathrm{~h}$ of incubation, the viability in the majority of treatments was similar to the control, with the CPI close to $100 \%$, except for $\mathrm{MVC}_{16}-31-20$ at $0.4 \mathrm{mg} / \mathrm{mL}$, where it was close to $75 \%$. Fibroblasts and macrophages had the typical flattened and spread morphology and no cell death was noticed at any concentration of nanogel used.

LDH assay is a non-radioactive, precise, fast and simple colorimetric assay suitable for high-throughput quantification of cell death and lysis, based on measurement of
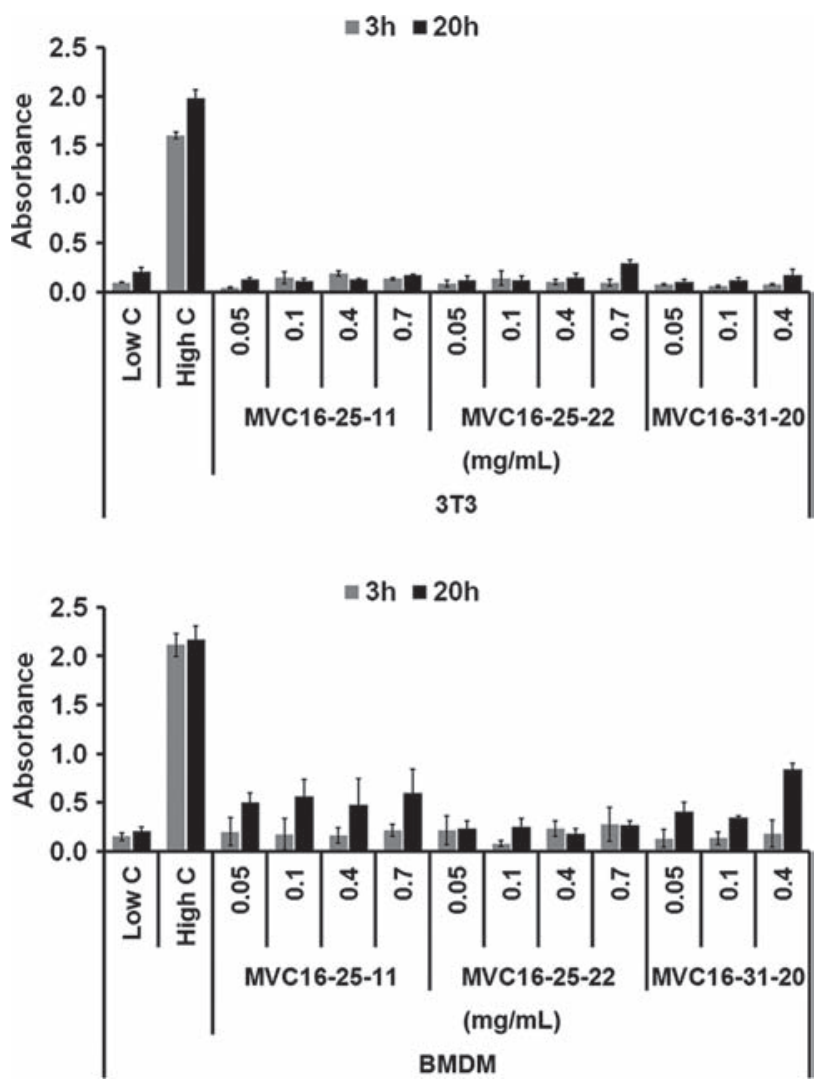

Fig. 2. Cytotoxic effect of mannan nanogel, at the indicated concentrations, in mouse embryo fibroblast 3T3 cells and BMDM, assessed with the LDH assay. Results represent the mean \pm S.D. ( $n=3$ per group) of the obtained absorbance measurements at $3 \mathrm{~h}$ and $20 \mathrm{~h}$ of incubation of the different nanogel samples, low control (Low C) and high control (High C), as indicated. Statistical significant differences $(p<0.01)$ within results were obtained with all tested concentrations of different nanogel samples in comparison with the High $\mathrm{C}$, at same incubation period, for both fibroblasts and macrophages. The results shown are from one experiment, representative of two independent experiments. 

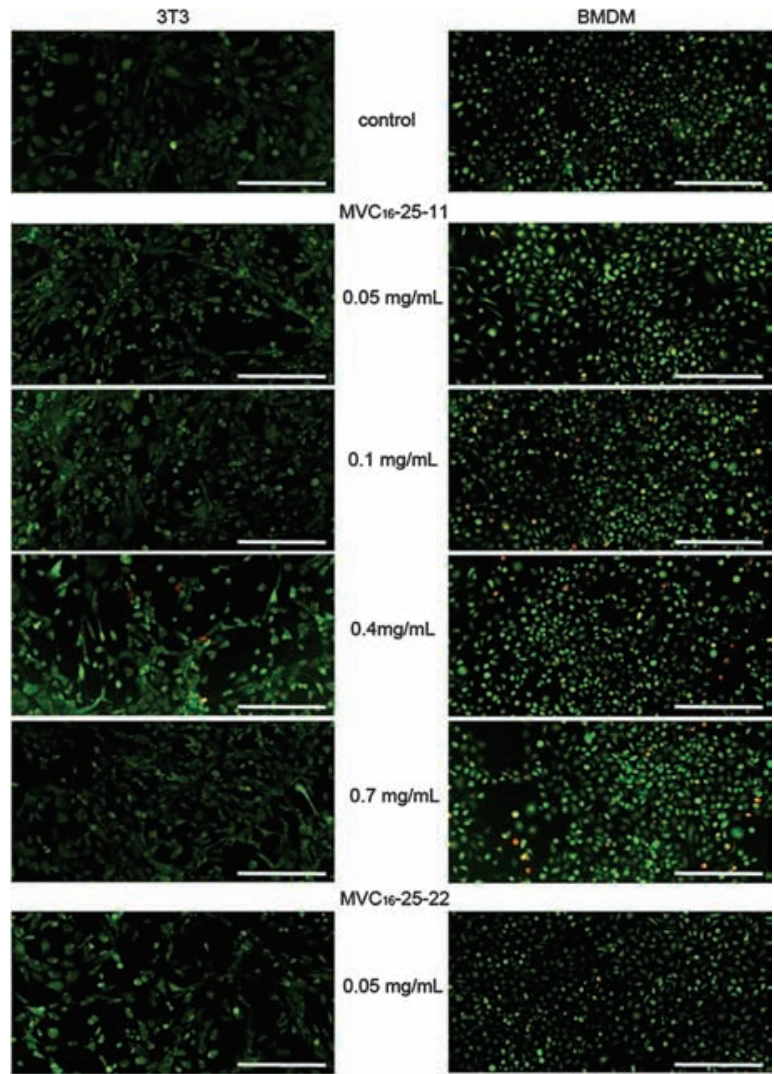

$\mathrm{MVC}_{16-25-22}$
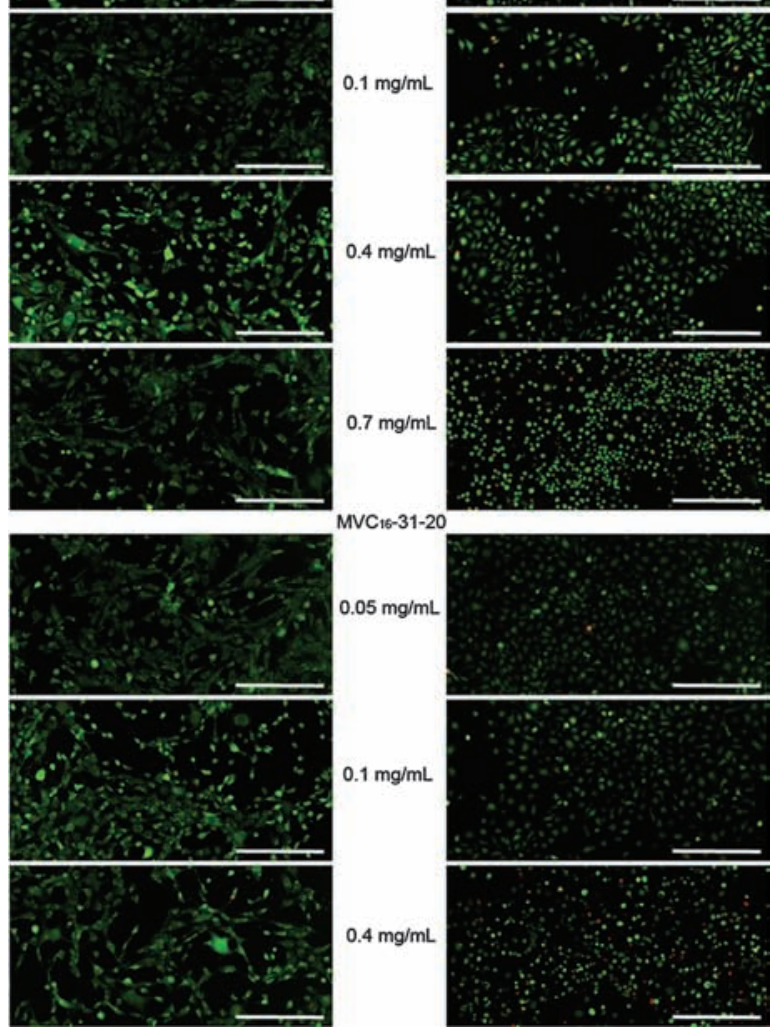

$0.05 \mathrm{mg} / \mathrm{mL}$
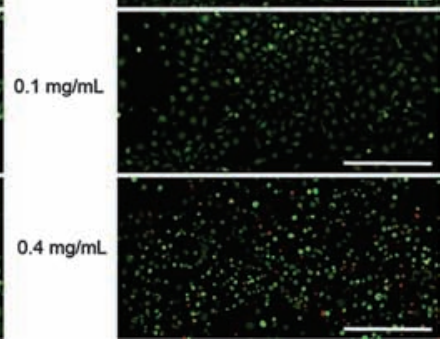

Fig. 3. Fluorescence images of mouse embryo fibroblast $3 \mathrm{~T} 3$ cells (left) and BMDM (right) stained using a Live/Dead ${ }^{\circledR}$ viability/cytotoxicity kit at $24 \mathrm{~h}$ of incubation in absence (control) or presence of mannan nanogel. Live cells are stained in green and dead cells are stained in red (scale bar $=200 \mu \mathrm{m})$.
LDH activity released from the cytosol of cells with damaged plasma membranes. LDH assay (Fig. 2) was used to evaluate the cytotoxicity of mannan nanogel in smaller periods of incubation. All treatments originated values of absorbance similar to low control, which determines the LDH activity released from the untreated healthy cells and corresponds to the spontaneous LDH release. Results were significantly $(p<0.01)$ lower than the high control, which determines the maximum releasable LDH activity in the cells and corresponds to the maximum LDH release.

The nontoxicity of mannan nanogel to mouse embryo fibroblast 3T3 cells and mouse BMDM, after $24 \mathrm{~h}$ of incubation, was further confirmed by Live/Dead assay (Fig. 3). The Live/Dead assay is a two-color fluorescence cell viability assay, that measures intracellular esterase activity and plasma membrane integrity, based on the simultaneous determination of live (green fluorescence) and dead cells (red fluorescence) with two probes, which are calcein, a polyanionic dye retained within living cells, and an ethidium bromide homodimer dye that enters the cells through damaged membranes, binding to nucleic acids, but is excluded by the intact plasma membrane of living cells. Only morphological changes were detected in life mouse BMDM for $\mathrm{MVC}_{16}-25-22$ at $0.7 \mathrm{mg} / \mathrm{mL}$ and $\mathrm{MVC}_{16}-31-20$ at $0.4 \mathrm{mg} / \mathrm{mL}$, where the number of dead cells was slightly bigger when compared with the control.

The alkaline comet assay (or single cell gel electrophoresis assay) is a useful technique for the evaluation of DNA damage at the single cell level and is a sensitive biological indicator in the evaluation of the genotoxicity in cell lines or primary cells. ${ }^{23-26}$ The comet assay is based on the ability of negatively charged loops/fragments of DNA to be drawn through an agarose gel under the force of an electric field. The extent of DNA migration is dependent on the DNA damage within cells. ${ }^{26,27}$ The advantages of using the comet assay, comparatively to other genotoxicity tests, include its high sensitivity for detecting low levels of both single and double stranded breaks in damaged

Table II. DNA damage in mouse embryo fibroblast 3T3 cells and BMDM caused by mannan nanogel at 0.1 and $0.4 \mathrm{mg} / \mathrm{mL}$ in comparison with control (untreated cells) after $24 \mathrm{~h}$ and $48 \mathrm{~h}$ of incubation, expressed in tail DNA intensity (\%). The results shown are from one representative experiment preformed in duplicate.

\begin{tabular}{lccc}
\hline \multicolumn{4}{c}{ Tail DNA intensity (\%) } \\
\hline \multirow{4}{*}{ control } & \multicolumn{2}{c}{ MVC $_{16}-31-20$} \\
\cline { 3 - 4 } & & $3 \mathrm{~T} 3$ & $0.4 \mathrm{mg} / \mathrm{mL}$ \\
\hline & & $2.04 \pm 2.34$ & $2.51 \pm 2.82$ \\
$24 \mathrm{~h}$ & $3.03 \pm 3.86$ & $5.05 \pm 4.48$ & $4.83 \pm 5.49$ \\
$48 \mathrm{~h}$ & $2.37 \pm 4.36$ & $\mathrm{BMDM}$ & \\
& & $13.77 \pm 11.63$ & $26.48 \pm 19.45^{* *}$ \\
$24 \mathrm{~h}$ & $9.76 \pm 9.84$ & $16.00 \pm 13.07^{* *}$ & $8.78 \pm 9.23$ \\
$48 \mathrm{~h}$ & $7.39 \pm 12.80$ &
\end{tabular}

(mean \pm S.D., ${ }^{* *} p<0.01$ ). 


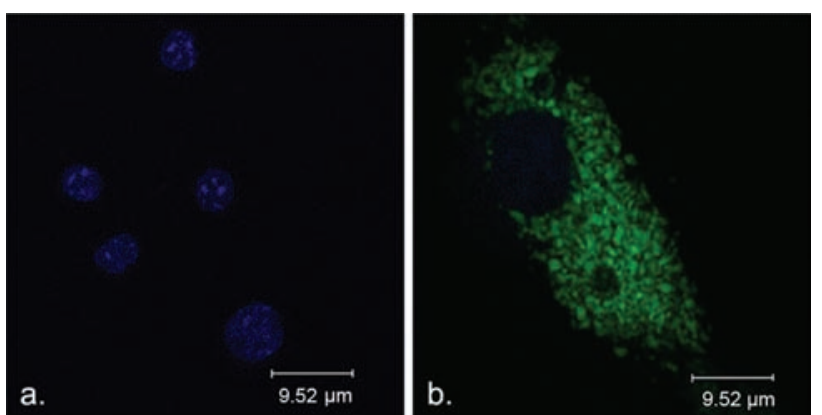

Fig. 4. Confocal images of mouse BMDM incubated $6 \mathrm{~h}$ without (a) and with (b) mannan nanogel labeled with SAMSA fluorescein at $0.1 \mathrm{mg} / \mathrm{mL}$ (green fluorescence). Nuclei of fixed cells are stained with DAPI (blue fluorescence). Images correspond to a central $Z$-stack of a representative experiment preformed in duplicate.

DNA, the requirement for small numbers of eukaryotic cells per sample, flexibility, low cost, and ease and rapid of application. ${ }^{26-28}$

Comet assay has been described as a reproducible assay to evaluate nanoparticles genotoxicity. ${ }^{29-34}$ Upon fluorescent staining, a 'Comet'-like structure is visualized with a circular head and a tail extending toward the anode due to the overall negative charge of DNA damaged. The genotoxicity caused by mannan nanogel at 0.1 and $0.4 \mathrm{mg} / \mathrm{mL}$ was evaluated in comparison to control (untreated cells) after $24 \mathrm{~h}$ and $48 \mathrm{~h}$ of incubation, attending the tail intensity (\%), which is expected to be proportional to the level of single strand breaks, crosslinks and alkalilabile sites (Table II). The nanogel does not induce DNA damage in mouse embryo fibroblast $3 \mathrm{~T} 3$ cells under the concentrations tested, as the negative control and samples with nanogel presented similar results. A statistically significant $(p<0.01)$ induction of DNA damage was observed in mouse BMDM after $24 \mathrm{~h}$ of exposure to $0.4 \mathrm{mg} / \mathrm{mL}$ and after $48 \mathrm{~h}$ of exposure to $0.1 \mathrm{mg} / \mathrm{mL}$ of mannan nanogel as compared to the respective control cells.

Table III. Colocalization coefficient $C_{\mathrm{T}}$ calculated by confocal image analysis throughout the entrance and exit of mannan nanogel and FM 4-64 in cytoplasm of mouse BMDM.

\begin{tabular}{lcccc}
\hline & Entrance & & \multicolumn{2}{c}{ Exit } \\
\cline { 5 - 5 } time (h) & $C_{\mathrm{T}}$ & & time (h) & $C_{\mathrm{T}}$ \\
\hline Control & 0.00 & 0 & 0.50 \\
0.5 & 0.19 & 0.25 & 0.46 \\
0.75 & 0.39 & 0.5 & 0.42 \\
1 & 0.34 & 0.75 & 0.43 \\
1.25 & 0.28 & 1 & 0.43 \\
1.5 & 0.38 & & \\
1.75 & 0.40 & & \\
2 & 0.43 & & \\
2.25 & 0.46 & & \\
2.5 & 0.41 & & \\
2.75 & 0.45 & & \\
3 & 0.51 & & \\
\hline
\end{tabular}

\subsection{Uptake of Mannan Nanogel by the BMDM}

The full viability of cells was ensured for the experimental concentration of $0.1 \mathrm{mg} / \mathrm{mL}$ used throughout confocal studies. $Z$-series confocal images of fixed phagocytic BMDM revealed that mannan nanogel is internalized in presence of LPS/IFN- $\gamma$. Upon internalization mannan nanogel labeled with SAMSA fluorescein (in green) is apparently present in vesicles, as could be inferred from the non-even distribution over the cytoplasm, and concentration of the fluorescence in internalized structures (Fig. 4). Similar internalization results were obtained in the absence of LPS/IFN- $\gamma$ (data not shown).

In live cells studies, cell viability was guaranteed at all confocal conditions and parameters, such as lasers intensity, temperature, $\mathrm{CO}_{2}$, fluoroprobes concentration, time of incubation, number $z$-series and time-series. In the absence of nanogel (control) cells labeled with DAPI, FM 4-64 and PI showed residual cell death randomly distributed in all fluorodish over time analysis (data not shown).

The visual-based evaluation of the extent of colocalization is prone to error and bias, as the 'amount of yellow' resultant from the superposition of one fluorescence image, pseudo-colored 'green', on image two, colored 'red' depends on the brightness of the merged images, the monitor settings, as well as the viewer's perception. Qualitative colocalization based on an image-overlay method was not possible due to the lower resultant green signal from the labeled nanogel when compared with the red signal intensity of FM 4-64. Therefore the colocalization was quantified in cytoplasm by image analysis. Colocalization can be explained as an existence of the signal generated by two or more different fluorochromes at the same three-dimensional volume, voxel, when examining multichannel fluorescence microscopy images of a sample region. The colocalization of two or more markers within cellular structures gives information about structural and functional characteristics of the molecular populations ${ }^{35}$ but not necessarily means molecular interaction or functional relationship. Colocalization coefficient in total pixels area $\left(C_{\mathrm{T}}\right)$ obtained by threshold-based analysis (annotation) increased over time when cells were incubated with nanogel and FM 4-64 in culture medium showing the entrance of labeled nanogel and of FM 4-64 to the cytoplasm of the viable cells. When nanogel and FM 4-64 were removed and cells were incubated in fresh medium, $C_{\mathrm{T}}$ reduced over time of incubation denoting the exit of both FM 4-64 and labeled nanogel from the cells. One hour was not enough for cells to release all previously internalized nanogel and FM 4-64 (Table III and Fig. 5). According to the $C_{\mathrm{T}}$ values the entrance and exit of nanogel and FM 4-64 in BMDM are associated. As FM 4-64 is a marker of endocytosis and exocytosis in eukaryotic cells, it is plausible that mannan nanogel entrance and exit in BMDM occurs by the same processes. More studies are necessary 

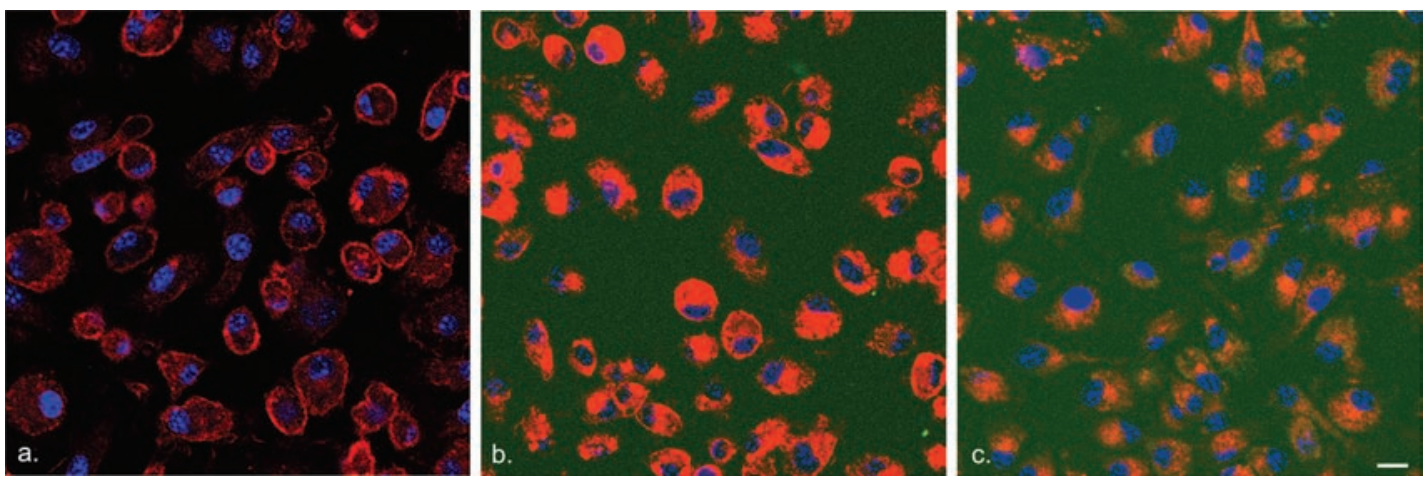

Fig. 5. Confocal microscopy analysis of entrance and exit of mannan nanogel using live mouse BMDM. Confocal images at a certain $Z$-stack (scale $\mathrm{bar}=10 \mu \mathrm{m}$ ) of a representative experiment of three independent experiments: (a) control cells labeled with DAPI (blue fluorescence) and FM 4-64 (red fluorescence); (b) cells after $3 \mathrm{~h}$ of incubation with the nanogel at $0.1 \mathrm{mg} / \mathrm{mL}$ (green fluorescence) and FM 4-64 present in culture medium; (c) cells after $1 \mathrm{~h}$ of incubation in fresh culture medium. PI was used to screen the viability of the cells.

to better understand the macrophage uptake mechanism of mannan nanogel.

\section{CONCLUSIONS}

The mannan nanogel is biocompatible to mouse embryo fibroblast 3T3 cells and mouse BMDM. Essentially, no cytotoxic effect was observed with mannan nanogel up to about $0.4 \mathrm{mg} / \mathrm{mL}$ in in vitro experiments using MTS, LDH, Live/Dead assays, and no significant differences were caused by differences in the DS of batches. Cell survival rate only dropped significantly at higher tested concentration after $48 \mathrm{~h}$ of incubation. Comet assay, under tested conditions, revealed no DNA damage in mouse embryo fibroblast $3 \mathrm{~T} 3$ cells but possible DNA damage in mouse BMDM. Upon internalization by mouse BMDM mannan nanogel is localized in vesicles, as judged by the non-even distribution over the cytoplasm, and concentration of the fluorescence in internalized structures. Exit of nanogel from the mouse BMDM was observed when cells were incubated in fresh medium. Confocal colocalization image analysis denotes that the entrance and exit of nanogel and FM 4-64 might occur by the same processes - endocytosis and exocytosis - in BMDM.

Acknowledgments: The author Sílvia A. Ferreira is the recipient of a fellowship from International Iberian Nanotechnology Laboratory (INL). The authors wish to acknowledge the financial support by Fundação para a Ciência e a Tecnologia (FCT, Portugal), trough PTDC. The technical support on confocal studies by Lucília Goreti Ribeiro Pinto from Life and Health Sciences Research Institute (ICVS), School of Health Sciences, Braga, Portugal, is gratefully acknowledged.

\section{References and Notes}

1. F. Ahsan, I. P. Rivas, M. A. Khan, and A. I. Torres Suárez, Targeting to macrophages: Role of physicochemical properties of particulate carriers - liposomes and microspheres - on the phagocytosis by macrophages. J. Control. Release 79, 29 (2002).

2. M. V. Park, D. P. Lankveld, H. van Loveren, and W. H. de Jong, The status of in vitro toxicity studies in the risk assessment of nanomaterials. Nanomedicine (Lond) 4, 669 (2009).

3. C. F. Jones and D. W. Grainger, In vitro assessments of nanomaterial toxicity. Adv. Drug Deliv. Rev. 61, 438 (2009).

4. S. A. Ferreira, P. Pereira, P. Sampaio, P. J. G. Coutinho, and F. M. Gama, Supramolecular assembled nanogel made of mannan. J. Colloid Interface Sci. 361, 97 (2011).

5. V. Apostolopoulos, G. A. Pietersz, B. E. Loveland, M. S. Sandrin, and I. F. McKenzie, Oxidative/reductive conjugation of mannan to antigen selects for T1 or T2 immune responses. Proc. Natl. Acad. Sci. USA 92, 10128 (1995).

6. X. G. Gu, M. Schmitt, A. Hiasa, Y. Nagata, H. Ikeda, Y. Sasaki, K. Akiyoshi, J. Sunamoto, H. Nakamura, K. Kuribayashi, and H. Shiku, A novel hydrophobized polysaccharide/oncoprotein complex vaccine induces in vitro and in vivo cellular and humoral immune responses against HER2-expressing murine sarcomas. Cancer Res. 58, 3385 (1998).

7. V. Sihorkar and S. P. Vyas, Potential of polysaccharide anchored liposomes in drug delivery, targeting and immunization. J. Pharm. Pharm. Sci. 4, 138 (2001)

8. A. Gupta, R. K. Gupta, and G. S. Gupta, Targeting cells for drug and gene delivery: Emerging applications of mannans and mannan binding lectins. J. Sci. Ind. Res. 68, 465 (2009).

9. A. Kaur, S. Jain, and A. K. Tiwary, Mannan-coated gelatin nanoparticles for sustained and targeted delivery of didanosine: In vitro and in vivo evaluation. Acta Pharm. 58, 61 (2008).

10. T. H. Kim, H. Jin, H. W. Kim, M.-H. Cho, and C. S. Cho, Mannosylated chitosan nanoparticle-based cytokine gene therapy suppressed cancer growth in BALB/c mice bearing CT-26 carcinoma cells. Molecular Cancer Therapeutics 5, 1723 (2006).

11. A. Avrameas, D. Mcllroy, A. Hosmalin, B. Autran, P. Debre, M. Monsigny, A. C. Roche, and P. Midoux, Expression of a mannose/fucose membrane lectin on human dendritic cells. Eur. J. Immunol. 26, 394 (1996).

12. M. Fukasawa, Y. Shimizu, K. Shikata, M. Nakata, R. Sakakibara, N. Yamamoto, M. Hatanaka, and T. Mizuochi, Liposome oligomannose-coated with neoglycolipid, a new candidate for a safe adjuvant for induction of CD8+ cytotoxic $T$ lymphocytes. FEBS Lett. 441, 353 (1998).

13. V. Apostolopoulos and I. F. McKenzie, Role of the mannose receptor in the immune response. Curr. Mol. Med. 1, 469 (2001).

14. Z. Cui and R. J. Mumper, Topical immunization using nanoengineered genetic vaccines. J. Control Release 81, 173 (2002). 
15. X. G. Gu, M. Schmitt, A. Hiasa, Y. Nagata, H. Ikeda, Y. Sasaki, K. Akiyoshi, J. Sunamoto, H. Nakamura, K. Kuribayashi, and H. Shiku, A novel hydrophobized polysaccharide/oncoprotein complex vaccine induces in vitro and in vivo cellular and humoral immune responses against HER2-expressing murine sarcomas. Cancer Res. 58, 3385 (1998).

16. H. Shiku, L. Wang, Y. Ikuta, T. Okugawa, M. Schmitt, X. Gu, K. Akiyoshi, J. Sunamoto, and H. Nakamura, Development of a cancer vaccine: Peptides, proteins, and DNA. Cancer Chemother. Pharmacol. S77 (2000).

17. R. J. Tushinski, I. T. Oliver, L. J. Guilbert, P. W. Tynan, J. R. Warner, and E. R. Stanley, Survival of mononuclear phagocytes depends on a lineage-specific growth factor that the differentiated cells selectively destroy. Cell 28, 71 (1982).

18. M. K. Warren and S. N. Vogel, Bone marrow-derived macrophages: Development and regulation of differentiation markers by colonystimulating factor and interferons. J. Immunol. 134, 982 (1985).

19. X. Zhang, R. Goncalves, and D. M. Mosser, The isolation and characterization of murine macrophages. Curr. Protoc. Immunol. Chap. 14, Unit 14.11 (2008).

20. N. P. Singh, M. T. McCoy, R. R. Tice, and E. L. Schneider, A simple technique for quantitation of low levels of DNA damage in individual cells. Exp. Cell Res. 175, 184 (1988).

21. T. Mosmann, Rapid colorimetric assay for cellular growth and survival: Application to proliferation and cytotoxicity assays. J. Immunol. Methods 65, 55 (1983).

22. J. A. Barltrop, T. C. Owen, A. H. Cory, and J. G. Cory, 5-(3-carboxymethoxyphenyl)-2-(4,5-dimethylthiazolyl)-3-(4sulfophenyl)tetrazolium, inner salt (MTS) and related analogs of 3-(4,5-dimethylthiazolyl)-2,5-diphenyltetrazolium bromide (MTT) reducing to purple water-soluble formazans as cell-viability indicators, Bioorg. Medicinal Chem. Lett. 1, 611 (1991).

23. D. Anderson and M. J. Plewa, The international comet assay workshop. Mutagenesis 13, 67 (1998).

24. D. Anderson, T.-W. Yu, and D. B. McGregor, Comet assay responses as indicators of carcinogen exposure. Mutagenesis 13, 539 (1998).
25. A. Collins, The comet assay for DNA damage and repair: Principles, applications, and limitations. Mol. Biotechnol. 26, 249 (2004).

26. R. R. Tice, E. Agurell, D. Anderson, B. Burlinson, A. Hartmann, H. Kobayashi, Y. Miyamae, E. Rojas, J. C. Ryu, and Y. F. Sasaki, Single cell gel/comet assay: Guidelines for in vitro and in vivo genetic toxicology testing. Environ. Mol. Mutagen. 35, 206 (2000).

27. A. R. Collins, A. A. Oscoz, G. Brunborg, I. Gaivão, L. Giovannelli, M. Kruszewski, C. C. Smith, and R. Stetina, The comet assay: Topical issues. Mutagenesis 23, 143 (2008).

28. A. R. Collins, V. L. Dobson, M. Duinská, G. Kennedy, and R. Stetina, The comet assay: What can it really tell us? Mutat. Res. 375, 183 (1997).

29. P. P. Dandekar, R. Jain, S. Patil, R. Dhumal, D. Tiwari, S. Sharma, G. Vanage, and V. Patravale, Curcumin-loaded hydrogel nanoparticles: Application in anti-malarial therapy and toxicological evaluation. J. Pharm. Sci. 99, 4992 (2010).

30. W. Vevers and A. Jha, Genotoxic and cytotoxic potential of titanium dioxide $\left(\mathrm{TiO}_{2}\right)$ nanoparticles on fish cells in vitro. Ecotoxicology 17, 410 (2008).

31. C. A. Barnes, A. Elsaesser, J. Arkusz, A. Smok, J. Palus, A. Lesniak, A. Salvati, J. P. Hanrahan, W. H. d. Jong, E. Dziubałtowska, M. Stepnik, K. Rydzynski, G. McKerr, I. Lynch, K. A. Dawson, and C. V. Howard, Reproducible comet assay of amorphous silica nanoparticles detects no genotoxicity. Nano Lett. 8, 3069 (2008).

32. S. Barillet, M. L. Jugan, M. Laye, Y. Leconte, N. Herlin-Boime, C. Reynaud, and M. Carrière, In vitro evaluation of $\mathrm{SiC}$ nanoparticles impact on A549 pulmonary cells: Cyto-, genotoxicity and oxidative stress. Toxicol. Lett. 198, 324 (2010).

33. T. N. Sathya, N. V. Vardhini, and P. Balakrishnamurthy, Revolution of 'nano' in in-vitro genetic toxicology. J. Cell Tissue Res. 10, 2389 (2010).

34. C. T. Ng, J. J. Li, B. H. Bay, and L. Y. Yung, Current studies into the genotoxic effects of nanomaterials. J. Nucleic Acids 2010 (2010).

35. V. Zinchuk, O. Zinchuk, and T. Okada, Quantitative colocalization analysis of multicolor confocal immunofluorescence microscopy images: Pushing pixels to explore biological phenomena. Acta Histochem. Cytochem. 40, 101 (2007).

Received: 28 September 2011. Accepted: 20 December 2011. 